\title{
PERANCANGAN DASHBOARD UNTUK VISUALISASI HARGA DAN PASOKAN BERAS DI PASAR INDUK BERAS CIPINANG
}

\section{DESIGNING DASHBOARD FOR PRICE VISUALIZATION AND RICE SUPPLY AT CIPINANG RICE MARKET}

\author{
Dedy Sugiarto $^{1)^{*}}$, Is Mardianto ${ }^{2)}$, Muhammad Najih'), Daniel Adrian ${ }^{3)}$, Dimas Adi Pratama ${ }^{2)}$ \\ ${ }^{1)}$ Program Studi Sistem Informasi, Universitas Trisakti, Jakarta \\ ${ }^{2)}$ Program Studi Informatika, Universitas Trisakti Jakarta \\ ${ }^{3)}$ Alumni Program Studi Teknik Elektro, Universitas Trisakti Jakarta \\ Jl. Kyai Tapa No. 1 Grogol, Jakarta 11440, Indonesia \\ E-mail: dedy@trisakti.ac.id
}

Makalah: Diterima 16 November 2020; Diperbaiki 1 Februari 2021; Disetujui 20 Februari 2021

\begin{abstract}
PT Food Station is a Regional Owned Enterprise of the DKI Jakarta Provincial Government which functions, among others, to manage inter-regional and inter-island rice trading centres as well as providing information related to rice price control in DKI Jakarta. Currently, the dashboard has not reached retail rice prices in various markets in Jakarta. This paper presents a dashboard that integrates price visualization at both the wholesale and retail levels as well as the supply of rice through the Cipinang Rice Main Market. The research stages consisted of identifying information needs, designing data warehouses and databases on On-line Analytical Processing (OLAP), acquisition of price data through Extract, Transform and Load (ETL) processes, and data visualization. The result was a data warehouse that stores several fact tables, namely the prices of various types of rice at wholesale and retail levels, quantity of incoming or outgoing rice and several dimension tables, namely the dimension of place (origin/destination city), time dimension, rice type dimension and market dimension as well as Dashboard a variety of price and supply charts that can be selected based on the available dimensions.
\end{abstract}

Keywords: dashboard, data warehouse, rice price, rice supply, visualization

\section{ABSTRAK}

PT Food Station merupakan Badan Usaha Milik Daerah milik Pemprov DKI yang berfungsi antara lain mengelola pusat perdagangan beras antar daerah dan antar pulau serta menyediakan informasi terkait pengendalian harga beras di DKI Jakarta. Saat ini dashboard yang dimiliki belum menjangkau harga beras eceran di berbagai pasar di Jakarta. Artikel ini menunjukkan sebuah dashboard yang mengintegrasikan visualisasi harga baik di tingkat grosir maupun eceran serta pasokan beras yang melalui Pasar Induk Beras Cipinang. Tahapan penelitian terdiri atas identifikasi kebutuhan informasi, perancangan data warehouse dan basis data On-line Analytical Processing (OLAP), akuisisi data harga melalui proses Extract, Transform and Load (ETL) serta visualisasi data. Hasilnya adalah sebuah data warehouse yang menyimpan beberapa tabel fakta, yaitu harga berbagai jenis beras di tingkat grosir dan eceran, kuantitas beras masuk atau keluar dan beberapa tabel dimensi, yaitu dimensi tempat (kota asal/tujuan), dimensi waktu, dimensi jenis beras serta dimensi pasar serta dashboard berbagai grafik harga dan pasokan yang dapat dapat dipilih berdasarkan dimensi yang tersedia.

Kata kunci : dashboard, data warehouse, harga beras, pasokan beras, visualisasi

\section{PENDAHULUAN}

Pasar Induk Beras Cipinang (PIBC) menjadi barometer harga beras dan menjadi acuan harga di pasar - pasar beras di sekitar Jakarta, Bogor, Depok, Tangerang dan Bekasi (Jabodetabek). PIBC biasanya dikunjungi oleh pejabat terkait setingkat menteri dan bahkan presiden sekalipun untuk memantau perkembangan harga dan stok beras menjelang bulan puasa dan lebaran. Sugiarto (2013) menjelaskan bahwa total pasokan beras ke PIBC mencapai ratarata 70.203 ton per bulan dengan minimum 48.322 ton serta maksimum 89.596 ton. Hal ini berarti bila dihitung dalam sebulan terdapat 30 hari maka kirakira per hari saat itu sekitar 2.340 ton. Berdasarkan hasil wawancara dengan pihak PT. Food Station selaku pengelola PIBC diketahui bahwa pasokan saat ini berkisar 2.500 s.d 3.000 ton per hari. Informasi harga dan stok beras yang senantiasa dipantau dibutuhkan juga untuk menentukan kapan waktu yang tepat untuk melakukan operasi pasar serta dampak evaluasi pasar pada penurunan harga. Saat ini waktu operasi pasar didasarkan pada beberapa indikator yaitu dalam satu minggu harga naik $10 \%$ atau dalam satu minggu pasokan kurang dari 1.500 ton/hari atau juga bila stok beras di bawah 25.000 ton.

Para pengambil keputusan di bidang perdagangan beras serta pihak pengelola PIBC membutuhkan ringkasan informasi secara cepat dan mudah dan tidak hanya pada harga di tingkat grosir 
namun juga informasi harga di tingkat eceran di berbagai pasar yang dikelola oleh Tim Pengendalian Inflasi Daerah (TPID) DKI Jakarta. Oleh sebab itu dirancanglah suatu bentuk dashboard yang dapat memvisualisasikan data secara terintegrasi baik di level grosir maupun eceran sekaligus informasi mengenai kuantitas pasokan beras dan stok. Rahman (2017) mengemukakan bahwa visualisasi muncul menjadi mekanisme umum untuk melakukan eksplorasi dan ekstraksi nilai dari dataset, baik bagi pemula maupun bagi analis ahli. Hal itu karena visualisasi data adalah mekanisme yang efektif untuk mengidentifikasi tren, wawasan dan anomali dalam suatu data. Alharthi (2017) menerangkan bahwa visualisasi data lebih berfokus untuk melihat berbagai hal secara berbeda, mencoba menarik kesimpulan yang beragam dalam mengambil keputusan, serta mempertimbangkan solusi yang berbeda bagi tantangan yang besar. Few (2006) menjelaskan bahwa dashboard berfungsi untuk mengubah data repositories menjadi informasi yang mudah dikonsumsi. Salah satu teknologi yang dapat digunakan dalam pembuatan dashboard adalah menggunakan Google Data Studio. Snipes (2018) menerangkan bahwa dashboard Google Data Studio yaitu suatu program yang memiliki fungsi utama sebagai alat interpretasi visual yang ramah pengguna untuk merepresentasikan kumpulan data yang kompleks.

Penelitian terkait pembangunan dashboard untuk visualisasi data antara lain pernah dilakukan oleh Fernando (2018) dengan membuat dashboard yang memvisualisasikan beragam data penjualan berbasis platform Google Data Studio serta Jayanti dan Ani (2017) yang membuat dashboard untuk analisa keuangan menggunakan berbagai perangkat lunak seperti SQL Server, Microsoft Visual Studio dan Microsoft Power BI. Pendekatan yang digunakan oleh Jayanti dan Ani (2017) dalam perancangan dashboard adalah menggunakan Nine Step Design Methodology yang juga umum dipakai dalam pembangunan data warehouse (Kimball dan Ross, 2013).

Sahay dan Ranjan (2008) menjelaskan bahwa data warehouse berkaitan erat dengan business intelligence karena berfungsi sebagai data repositories yang mengintegrasikan berbagai data mentah dan databases (point of sales, supply chain serta call center) yang dipasok ke business intelligence tools untuk mendapatkan berbagai hasil dalam bentuk grafik, laporan, alert, peramalan maupun data mining. Bachtiar (2017) menerangkan kegunaan dari memvisualisasikan data antara lain agar pengguna dapat melakukan penggalian informasi dengan cepat, memahami informasi dalam jumlah besar sehingga memungkinkan pengguna untuk melihat keterhubungan data, mempermudah dalam mengambil keputusan berdasarkan informasi yang ada, mengetahui gerak perubahan kondisi pasar dengan cepat, dan pengguna dapat berinteraksi langsung dengan data sehingga dapat merespon kejadian yang ada dengan cepat. Vinarti (2014) mengungkapkan bahwa berkat adanya dashboard maka dapat memudahkan para pemegang kepentingan menambahkan dan melihat dampak akan kebijakan yang telah dibuat.

\section{METODE PENELITIAN}

Secara umum tahapan penelitian terdiri atas identifikasi kebutuhan informasi, perancangan data warehouse, akuisisi data harga, pasokan dan stok serta terakhir adalah pembuatan dashboard menggunakan aplikasi Google Data Studio seperti dapat dilihat pada Gambar 1. Identifikasi kebutuhan informasi dilakukan melalui wawancara dengan salah seorang staf di PT. Food Station yaitu Kepala Pasar Induk Beras Cipinang. Perancangan data warehouse menggunakan tahapan dari Four Step Dimensional Design Process yang terdiri dari empat fase kunci yaitu pemilihan proses bisnis, deklarasi grain, identifikasi dimensi dan terakhir identifikasi fakta (Kimball dan Ross, 2013). Hasil dari perancangan data warehouse adalah terbentuknya rancangan basis data On-line Analytical Processing (OLAP).

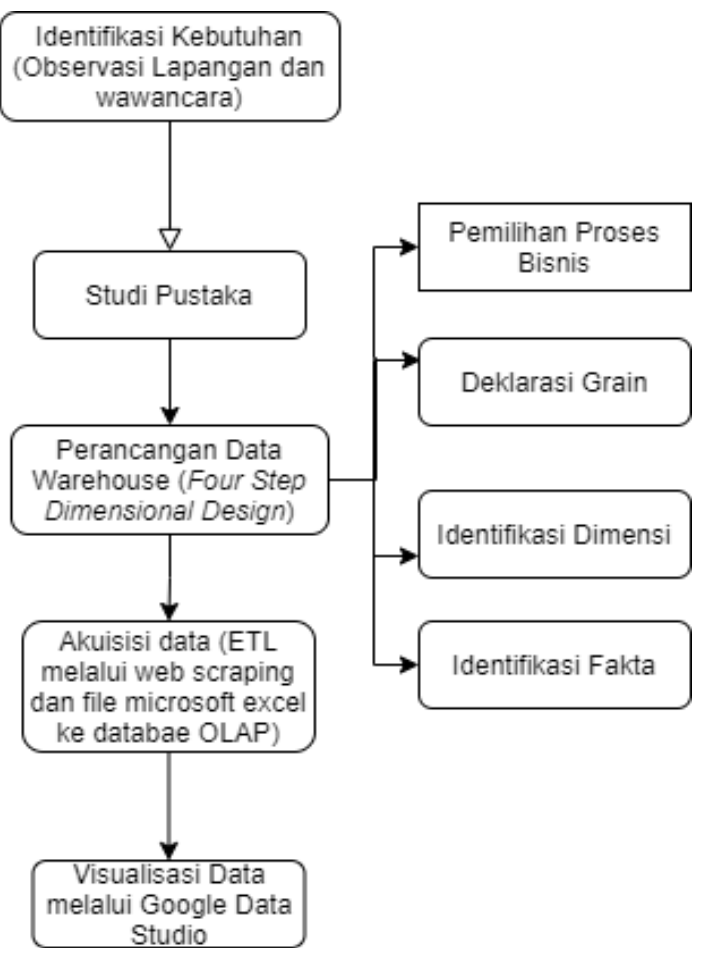

Gambar 1. Diagram alir metode penelitian

Akuisisi data dari file Excel harga harian yang bersumber dari PT. Food Station seperti terlihat pada Tabel 1 serta basis data info harga beragam jenis beras yang bertipe data JSON dari https://infopangan.jakarta.go.id . Proses akuisisi data secara lebih rinci dapat dilihat pada Gambar 2. Data dengan tipe JSON yang dijelaskan oleh Baazizi 
(2017) bahwa kumpulan datanya tidak memilki skema, yang mana hal tersebut memastikan adanya beberapa keunggulan, secara khusus aplikasi-aplikasi modern dapat dengan cepat mengkonsumsi data semiterstruktur dalam ukuran besar tanpa menunggu sebuah skema untuk menspesifikasikannya.

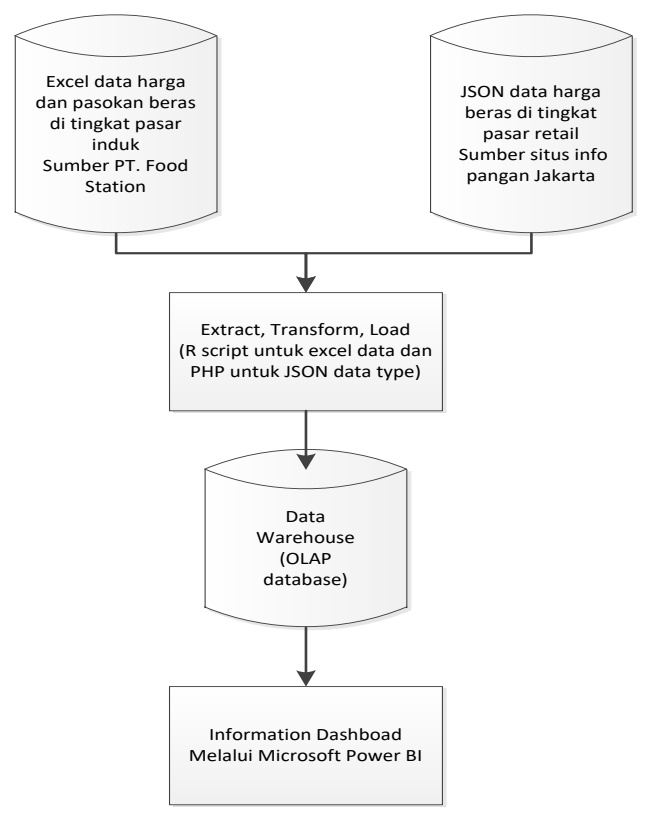

Gambar 2. Proses akuisisi data

Akuisisi data dari sumber-sumber yang ada dikumpulkan untuk kemudian disiapkan menuju proses ETL. Supaya dapat dimasukkan kedalam database maka data yang ada harus dinormalisasi terlebih dahulu. Hal tersebut dilakukan khususnya untuk data yang terdapat pada https://infopangan.jakarta.go.id/. Proses perancangan arsitektur data warehouse ini melihat jenis sumber data yang akan diolah sehingga metode pengolahan datanya untuk masuk ke dalam proses ETL dapat berjalan dengan baik.

Selanjutnya proses akuisisi data ke dalam database dilakukan melalui proses Extract,
Transform, Load (ETL). Menurut Nath (2017) proses ETL ini merupakan proses inti atau tulang punggung dari proses data warehouse secara keseluruhan. Dalam hal ini, data awal yang digunakan yang bersumber dari Pasar Induk Beras Cipinang dalam format Microsoft Excel, sehingga memungkinkan untuk dilakukan proses ETL menggunakan R script secara langsung. Sementara itu pada sumber yang menyediakan data dari pasar-pasar retail lainnya, format yang disediakan berupa JSON yang ada pada situs https://infopangan.jakarta.go.id/ yang mana hal tersebut mengharuskan proses ETL dilakukan melalui scrapping data menggunakan PHP. Ketika seluruh elemen telah dirancang dengan baik, maka proses ETL dapat dijalankan dengan melakukan konversi bentuk data dari masing-masing sumber menuju satu bentuk data yang sudah disesuaikan sebelumnya. Terakhir dilakukanlah proses visualisasi data dari basis data menuju dashboard aplikasi Google Data Studio.

\section{HASIL DAN PEMBAHASAN}

Kebutuhan informasi terhadap dashboard yang dirancang adalah untuk mampu menampilkan grafik deret waktu (time series plot) harga beras berdasarkan 14 jenis beras yang umum diperdagangkan di PIBC (seperti Cianjur Kepala, Cianjur Slyp, Setra, Saigon, Muncul I, Muncul II, Muncul III, IR-64 I, IR-64 II, IR-64 III, IR-42, ketan putih biasa, ketan putih paris, dan ketan hitam), jenis pasar serta rentang waktu penyajian grafik. Selain itu, dashboard juga dapat menampilkan grafik batang perbandingan rerata harga dari 14 jenis beras berdasarkan pasar retail atau eceran yang sudah dipilih sebelumnya. Grafik batang yang dihasilkan tidak dibatasi jumlah pasar retail serta jenis beras yang akan diperiksa. Selain daripada itu, dashboard juga diharapkan dapat menampilkan diagram lingkaran jumlah pasokan beras masuk dan keluar PIBC yang dapat dipilih berdasarkan kota asal (beras masuk) dan kota tujuan (beras keluar) serta dapat menampilkan informasi jumlah stok beras di PIBC.

Tabel 1. Sampel data harga dari PT. Food Station dalam format excel

\begin{tabular}{llllllllllllllll}
\hline Tgl & $\begin{array}{l}\text { Cianjur } \\
\text { Kepala } \\
\text { (Pandan) }\end{array}$ & $\begin{array}{l}\text { Cianjur } \\
\text { Slyp } \\
\text { (Pandan }\end{array}$ & Setra & Saigon & $\begin{array}{l}\text { Muncul } \\
\mathbf{l}\end{array}$ & & $\begin{array}{l}\text { Muncul } \\
\text { II }\end{array}$ & $\begin{array}{l}\text { Mun } \\
\text { cul } \\
\text { III }\end{array}$ & IR-64 I & $\begin{array}{l}\text { IR-64 } \\
\text { II }\end{array}$ & $\begin{array}{l}\text { IR-64 } \\
\text { III }\end{array}$ & $\begin{array}{l}\text { IR-42 } \\
\text { (Pera) }\end{array}$ & $\begin{array}{l}\text { Ketan } \\
\text { Putih } \\
\text { Biasa }\end{array}$ & $\begin{array}{l}\text { Ketan } \\
\text { Putih } \\
\text { Paris }\end{array}$ & $\begin{array}{l}\text { Ketan } \\
\text { Hitam }\end{array}$ \\
\hline 1 & 13,475 & 12,425 & 13,250 & 11,825 & 11,075 & 10,450 & 9,875 & 10,450 & 9,750 & 8,650 & 10,825 & 13,025 & 18,725 & 19,300 \\
2 & 13,450 & 12,400 & 13,250 & 11,825 & 11,075 & 10,425 & 9,875 & 10,450 & 9,750 & 8,650 & 10,850 & 13,025 & 18,750 & 19,300 \\
3 & 13,450 & 12,400 & 13,250 & 11,825 & 11,075 & 10,425 & 9,875 & 10,450 & 9,725 & 8,650 & 10,850 & 13,025 & 18,750 & 19,300 \\
4 & 13,425 & 12,400 & 13,250 & 11,825 & 11,075 & 10,425 & 9,875 & 10,450 & 9,725 & 8,650 & 10,850 & 13,000 & 18,750 & 19,300 \\
5 & 13,425 & 12,400 & 13,250 & 11,825 & 11,075 & 10,425 & 9,875 & 10,450 & 9,725 & 8,650 & 10,850 & 13,000 & 18,775 & 19,300 \\
\hline
\end{tabular}


Kegiatan bisnis utama perusahaan terkait dengan posisi perusahaan sebagai pengelola tunggal PIBC yang harus memastikan pasokan beras aman dimana stok beras dijaga tetap di atas 30.000 ton setiap harinya. Secara umum jasa utama yang diselenggarakan perusahaan adalah jasa pertokoan, jasa pergudangan, jasa pengangkutan, resi gudang serta penyediaan informasi perdagangan beras berupa informasi harga dan stok serta bisnis beras yang meliputi pengadaan, pengolahan beras modern serta penjualan beras dengan merek FS. Ada pula bisnis perdagangan lainnya yang dijalankan yaitu penjualan minyak goreng dan gula tebu yang masih dibawah merek FS.

Pemilihan grain terkait dengan penentuan yang akan dipresentasikan oleh sebuah tabel fakta atau oleh record di dalam tabel fakta. Grain yang digunakan untuk merancang data warehouse adalah harga, kuantitas beras masuk, kuantitas beras keluar dan stok beras. Pada Tabel 2 dapat dilihat hubungan dimensi dengan grain dari fakta dalam bentuk matriks.

Tabel 2. Grain dan dimensi

\begin{tabular}{lllll}
\hline $\begin{array}{l}\text { Grain } \\
\text { Dimensi }\end{array}$ & $\begin{array}{l}\text { Harga } \\
\text { beras }\end{array}$ & $\begin{array}{l}\text { Kuantitas } \\
\text { beras } \\
\text { masuk }\end{array}$ & $\begin{array}{l}\text { Kuantitas } \\
\text { beras } \\
\text { keluar }\end{array}$ & Stok \\
\hline $\begin{array}{l}\text { Waktu } \\
\text { Nama }\end{array}$ & $\mathrm{x}$ & $\mathrm{x}$ & $\mathrm{x}$ & $\mathrm{x}$ \\
$\begin{array}{l}\text { Pasar } \\
\text { Jenis }\end{array}$ & $\mathrm{x}$ & & & \\
$\begin{array}{l}\text { Beras } \\
\text { Tempat } \\
\text { (Kota) }\end{array}$ & & $\mathrm{x}$ & $\mathrm{x}$ & $\mathrm{x}$ \\
\hline
\end{tabular}

Beragam jenis data yang ada dari beberapa dimensi dapat direlasikan kepada beberapa data grain yang sudah didapatkan. Hal ini digunakan untuk membangun struktur database yang ternormalisasi. Hasil penghubungan relasi tersebut disimpan kedalam tabel baru didalam database bernama fact table atau tabel fakta. Hubungan antara tabel fakta dan tabel dimensi dapat dilihat pada skema bintang pada Gambar 3 sampai dengan Gambar 6 di bawah ini.

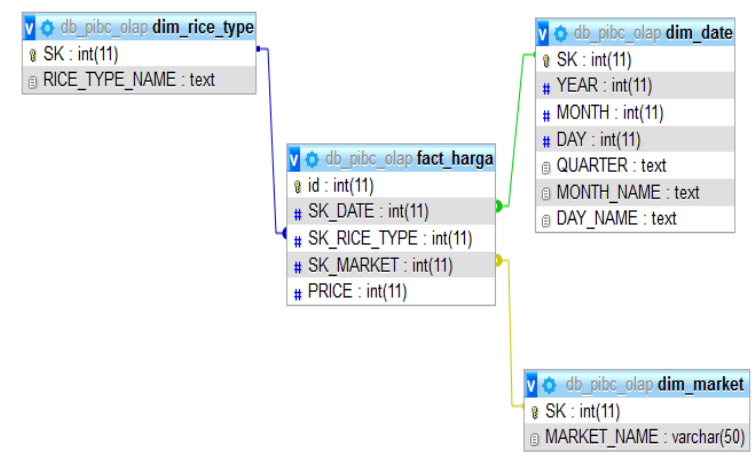

Gambar 3. Diagram bintang fact_harga
Untuk menyimpan data harga beragam jenis beras berdasarkan tipe berasnya, tanggalnya, serta lokasi pasarnya maka dapat dilakukan relasi antara tabel dim_date, dim_rice_type dan dim_market untuk membentuk satu tabel baru bernama fact_harga (Gambar 3).

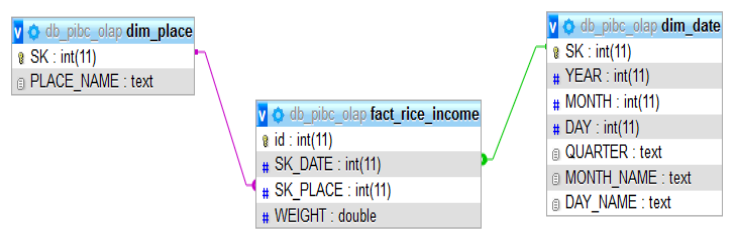

Gambar 4. Diagram bintang fact_rice_income

Kemudian untuk menyimpan informasi mengenai stok beras yang masuk berdasarkan tanggalnya dapat dilakukan relasi antara tabel dim_date dengan dim_location untuk membentuk tabel baru bernama fact rice income yang dimasuki oleh data grain berupa kuantitas beras masuk (Gambar 4).

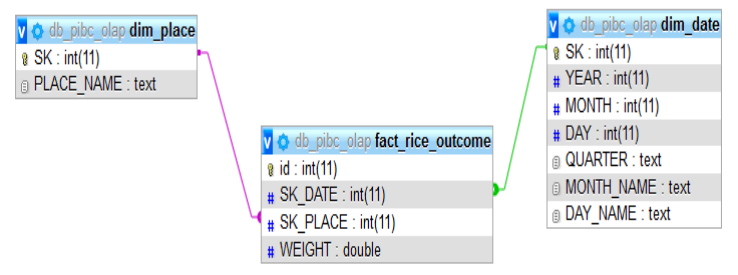

Gambar 5. Diagram bintang fact_rice_outcome

Selanjunya, penyimpanan informasi untuk jumlah stok beras yang keluar juga dapat dilakukan. Sama dengan proses pada Gambar 4 yang membedakan hanyalah data grain kuantitas beras keluar yang dimasukan kedalam tabel fact_rice_outcome (Gambar 5).

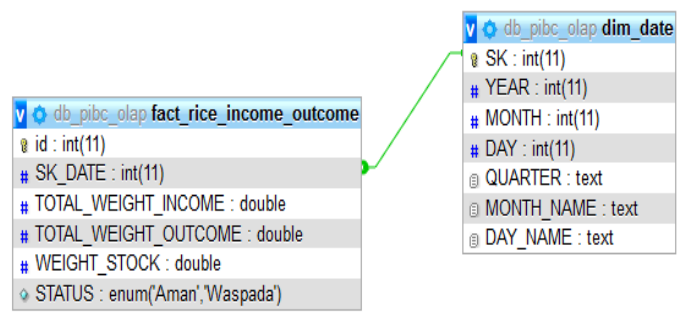

Gambar 6. Diagram bintang fact rice income outcome

Terakhir, untuk melihat kuantitas total dari stok beras yang tersedia (tanpa melihat tempat asal dan tujuan dari beras tersebut berpindah) maka tabel fact_rice_income_outcome dapat dibentuk dengan merelasikan tabel dim_date dan menambahkan grain kuantitas beras masuk, kuantitas beras keluar serta 
tambahan kolom yang menandakan status kecukupan dari stok beras yang ada (Gambar 6).

Setelah struktur basis data dihasilkan maka proses akuisi bisa dijalankan. Data yang terdapat pada berbagai sheet di file excel PT. Food Station serta data dari info pangan Jakarta diintegrasikan menjadi sebuah database OLAP yang dinamakan $d b$ pibc_olap. Proses ETL dalam penelitian ini bermakna migrasi data dari data harga dan pasokan beras dari PIBC dengan fomat Excel yang berasal dari PT. Food Station dan data berformat JSON dari situs https://infopangan.jakarta.go.id/ menuju data warehouse dimana proses ini akan dilakukan setiap bulan. Durasi waktu dari data yang dimasukkan ke dalam data warehouse adalah data 4 tahun terakhir mulai 2016- 2019. Proses pemindahan data baru ke dalam data warehouse dilakukan setiap awal bulan.

Proses selanjutnya setelah data tersimpan di data warehouse adalah memanggil database tersebut di Google Data Studio serta melakukan kustomisasi sumber data seperti dapat dilihat pada Gambar 7.
Penambahan kolom yang diatur secara kustom seperti kolom SK_RICE_TYPE_string berguna untuk mengintegrasikan atribut yang sama dari satu tabel dengan tabel lainnya, khususnya atribut jenis beras.

Salah satu contoh tampilan dashboard grafik batang harga rerata beras sesuai dengan pasar yang dipilih, jenis beras dan tanggalnya dapat dilihat pada Gambar 8 (sisi kiri). Pengguna dapat memilih berdasarkan variabel yang akan ditampikan dan secara interaktif grafik batang akan terbentuk sesuai pilihan parameter yang diberikan. Terlihat pula pada gambar tersebut informasi harga eceran beras IR64III di Pasar Jembatan Merah bernilai sama dengan data yang bersumber dari situs info pangan Jakarta tertanggal 10 Januari 2019. Hal ini menunjukkan dashboard yang dihasil dari penelitian ini telah mampu mengintegrasikan data harga di tingkat grosir yang berasal dari PT. Food Station (PIBC) serta harga di tingkat eceran yang berasal dari situs info pangan Jakarta.

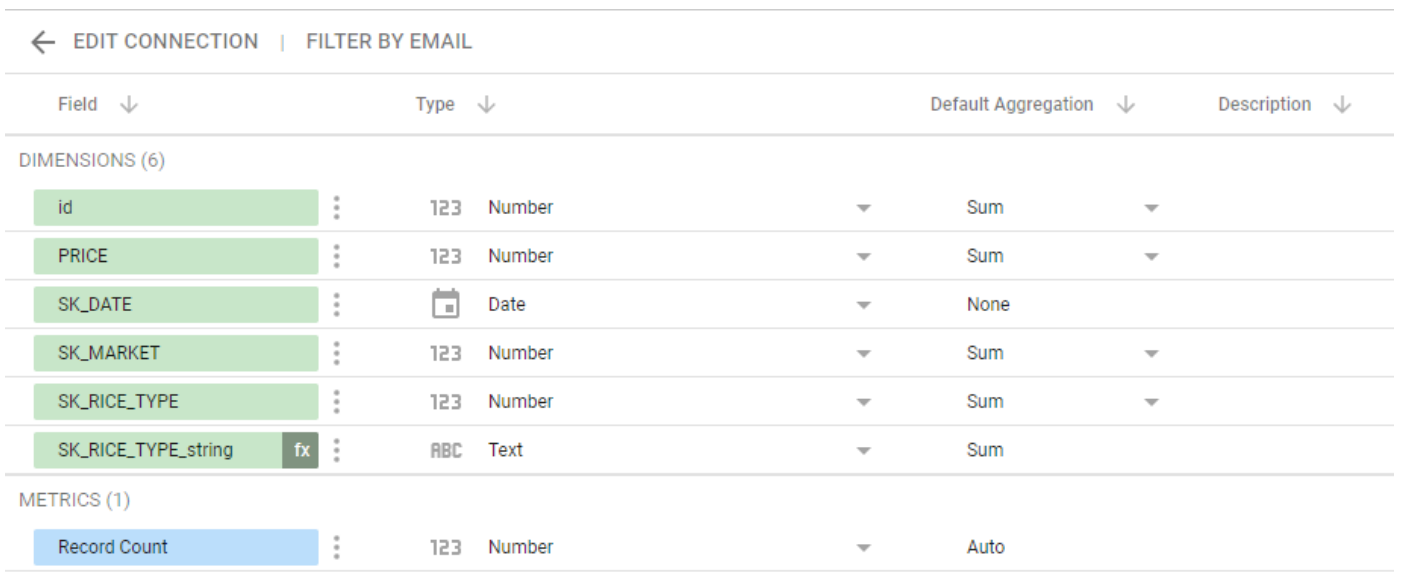

Gambar 7. Kustomisasi sumber data di Google Data Studio
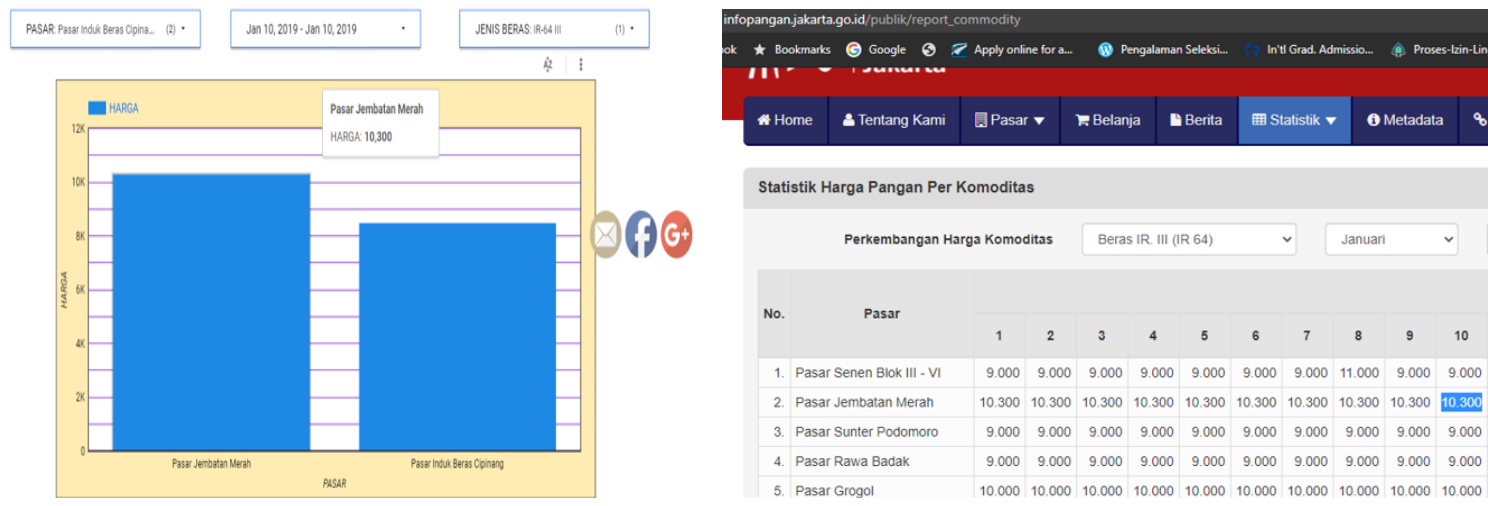

Gambar 8. Perbandingan tampilan grafik batang di Google Data Studio (sisi kiri) dan sumber data (sisi kanan) 
Kemudian untuk tampilan dashboard grafik deret waktu harga beras terlihat pada Gambar 9. Pengguna dapat memilih tipe beras yang akan ditampikan dan secara interaktif grafik garis akan bersisi plot deret waktu perkembangan harga sesuai tipe berasnya. Pengguna juga dapat mengatur rentang waktu yang ingin ditampilkan pada grafik timeseries ini sesuai dengan pilihan yang sudah ditentukan pengguna. Data yang ditampilkan pada Gambar untuk data tanggal 4 April 2018 dapat ditunjukkan bernilai sama dengan data yang dipublikasi oleh PT. Food Station (Gambar 10)

Tampilan grafik harga dengan pilihan jenis beras dan rentang waktu ini juga dapat digunakan untuk memonitor dampak dari pelaksanaan operasi pasar yang dilakukan oleh PT. Food Station bersama instansi terkait. Sebagai contoh operasi pasar beras medium yang pernah dilakukan adalah pada tanggal 22 November 2018 ketika harga mulai merangkak naik sebelum dilakukannya operasi pasar dan terlihat menurun setelahnya (Gambar 11).

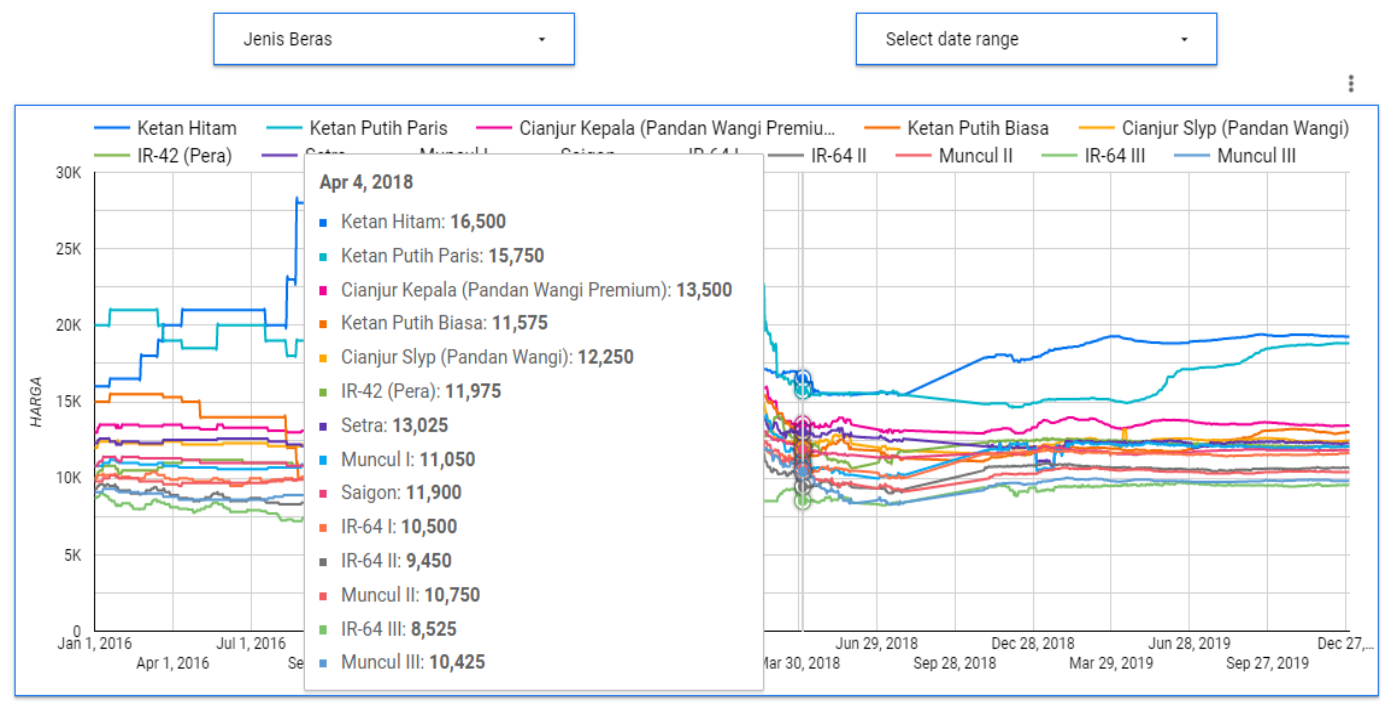

Gambar 9. Tampilan grafik deret waktu di Google Data Studio

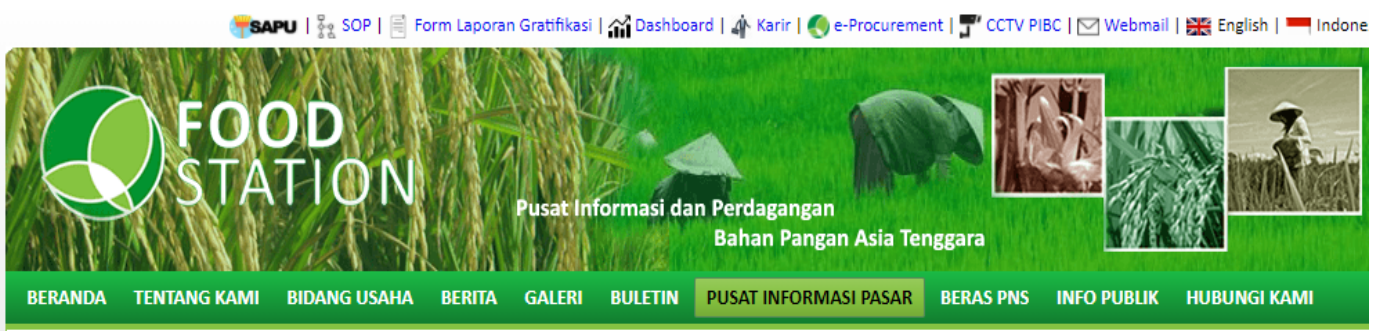

Anda disini: BERANDA , PUSAT INFORMASI PASAR , Harga Beras PIBC

Perkembangan Harga Rata-Rata Beras Grosir di PIBC

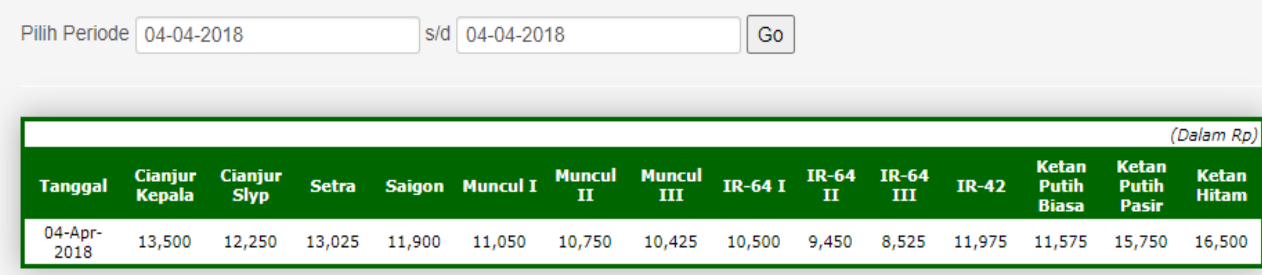

Gambar 10. Data harga beras tanggal 4 April 2018 yang bersumber dari PT. Food Station 


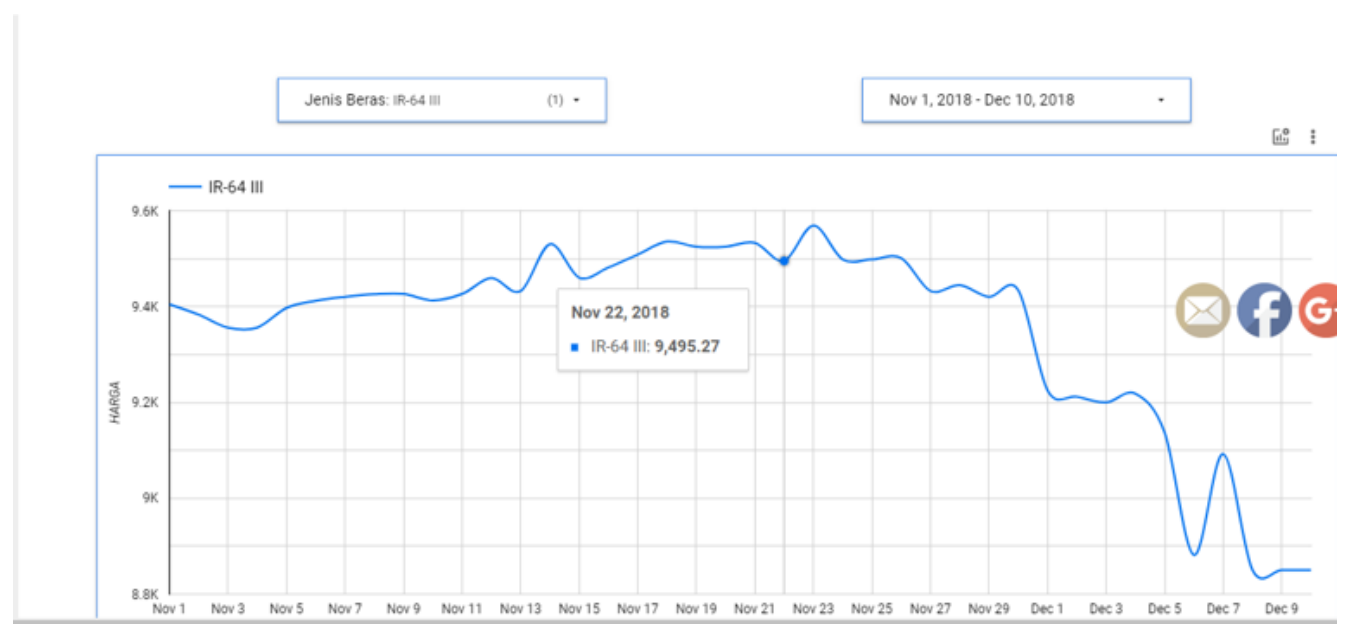

Gambar 11. Perbandingan tren harga sebelum dan sesudah operasi pasar beras medium tanggal 22 November 2018

Daerah Asal Pasokan Beras

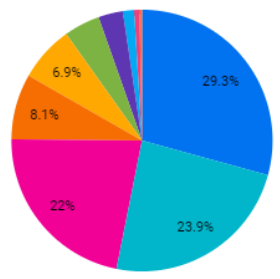

Cirebon

- Jawa Tengah

Bandung

- Ex Bulog

- Tanjung Priok

- Jawar Tumur

- Cianjur

Banten

Gambar 12. Diagram lingkaran daerah asal pasokan beras

Pasokan harga beras masuk dan beras keluar dari PIBC juga dapat ditampilkan dalam diagram lingkaran. Terlihat pada Gambar 12 adalah diagram lingkaran daerah asal pasokan beras (beras masuk) yang dipilih pada data 4 bulan pertama pada tahun 2017. Terlihat bahwa 4 daerah utama pemasok beras ke DKI Jakarta melalui PIBC adalah beras yang berasal dari Cirebon, Jawa Tengah, Karawang dan Bandung.

\section{KESIMPULAN DAN SARAN}

\section{Kesimpulan}

Berdasarkan perancangan dashboard yang telah dibuat menggunakan aplikasi Google Data Studio dengan dibantu dengan data warehouse untuk menyiapkan dan menormalisasikan datanya, maka dapat dihasilkan informasi rinci terkait harga beras berdasarkan beberapa variabel, seperti jenis beras, periode waktu serta jenis pasar. Di dalam dashboard juga dapat menampilkan informasi rinci terkait pasokan masuk dan pasokan keluar yang ada di PIBC. Hal ini diharapkan dapat mempermudah pengelola PIBC dalam melakukan pemantauan harga beras baik di tingkat pasar induk maupun di tingkat pasar retail di DKI Jakarta. Selain itu proses pengambilan keputusan juga dapat dilakukan lebih cepat dan efisien dengan adanya visualisasi data tersebut.

\section{Saran}

Penelitian dapat dikembangkan melalui penggunaan bahasa pemrograman $\mathrm{R}$ atau Python dalam pembuatan dashboard sehingga grafik yang ditampilkan dapat lebih kompleks seperti grafik perkiraan harga pada beberapa periode yang akan datang (timeseries forecasting) sebagai dasar untuk dilakukannya operasi pasar.

\section{DAFTAR PUSTAKA}

Alharthi N dan Gutub A. 2017. Data visualization to explore improving decision-making within hajj services. Scientific Modelling and Research. 2 (1): 9-18

Baazizi MA, Lahmar HB, Colazzo D, Ghelli G, Sartiani C. 2017. Schema Inference for Massive JSON Datasets. Extending Database Technology. (EDBT), 62.

Bachtiar AD, Dharmayanti D, dan Husnaisa H. 2017. Visualisasi data terbuka ketahanan pangan 
provinsi Jawa Barat. Jurnal Ilmiah Komputer dan Informatika. 6 (1): 16-23.

Fernando D. 2018. Visualisasi data menggunakan google data studio. In Prosiding Seminar Nasional Rekayasa Teknologi Informasi SNARTISI (Vol. 1)

Few S. 2006. Information Dashboard Design: The Effective Visual Communication of Data. Sebastopol : O'Reilly Media

Jayanti ED dan Ani E. 2017. Pembangunan dashboard untuk visualisasi analisa keuangan. Jurnal Format. 6 (2): 57-66.

Kimball R dan Ross M. 2013. The Data Warehouse Toolkit: The Definitive Guide to Dimensional Modeling, Third Edition. Indianapolis: Wiley Publishing, Inc.

Nath RPD, Hose K, Pedersen TB, Romero O. 2017. SETL: A programmable semantic extracttransform-load framework for semantic data warehouses. Information Systems. 68:17-43.

Sugiarto D, Surjasa D, Ratnawati N, Solihah B. 2013. Analisis statistika rantai pasok beras melalui pasar induk beras Cipinang. Proceedings Indonesian Statistical Analysis Conference. Bandung. 28 November 2013.
Rahman S, Aliakbarpour M, Kong HK, Blais E, Karahalios K, Parameswaran A, Rubinfield R. 2017. I've seen" enough" incrementally improving visualizations to support rapid decision making. Proceedings of the VLDB Endowment. 10 (11) : 1262-1273.

Sahay BSD dan Ranjan J. 2008. Real time business intelligence in supply chain analytics. Information Management \& Computer Security. 16 (1) : 28-48.

Snipes G. 2018. Google data studio. Journal Librarianship and Scholarly Communication. 6 (1):1-5.

Vinarti RA, Djunaidy A, Tyasnurita R, Raras HI. 2014. Analisis konseptual PD-Dash: pemanfaatan dashboard untuk visualisasi informasi dan penggalian data kependudukan. Conference: Seminar Nasional Sistem Komputer dan Informatika (SNSKI) 2014. 